\title{
Inclusion of Perfluoromethyl Groups in the Crystals of Copolymers of Tetrafluoroethylene and Hexafluoropropylene*
}

\author{
L. H. Bolz and R. K. Eby
}

(June 21, 1965)

\begin{abstract}
$\mathrm{X}$-ray diffraction has been used to measure the separation of the molecular axes as a function of temperature, lamella thickness, and comonomer concentration in copolymers of tetrafluoroethylene and hexafluoropropylene. These data show that the increase of separation with increasing concentration of perfluoromethyl groups is a consequence of inclusion of the groups in the crystals and not an artifact associated with lamella thickness or crystal transition temperature. This conclusion is supported by the fact that diffuseness of some of the $\mathrm{x}$-ray reflections in the copolymers indicates the presence of molecular disorder which might be expected from inclusion of the perfluoromethyl groups in the crystals. The lamellas in the copolymers are thinner than those in the typical homopolymer and this aspect of the structure is the primary cause of the lower density in the copolymers. Analysis of the available data indicates that this is also the situation in copolymers of ethylene and propylene. For both copolymer series, the density of the lamellas is apparently increased by the inclusion of the methyl groups in the crystals as defects.
\end{abstract}

\section{Introduction}

In an earlier article [1], ${ }^{1}$ evidence was presented that copolymers of tetrafluoroethylene and hexafluoropropylene form lamellar crystals with the perfluoromethyl groups within the crystals as point defects. Part of this evidence was the fact that the copolymer exhibited a larger separation of the molecular axes than did polytetrafluoroethylene. This result, which disagrees with a report of no change of separation [2], is subject to a question arising from the fact that polytetrafluoroethylene undergoes firstorder, crystal-crystal transitions at about 290 and $305^{\circ} \mathrm{K}[3,4]$. These transitions, at which both the lattice parameters and the thermal coefficients of expansion increase $[3,5]$ occur at lower temperatures in the copolymers. Thus, it can be asked whether the lattice of the copolymer is larger than that of polytetrafluoroethylene at $296^{\circ} \mathrm{K}$ merely because the copolymer is at a temperature which is further removed from the phase transition.

Another question arises from the fact that the lamella thickness was observed to decrease with increasing concentration of perfluoromethyl groups $[1]^{1}$ (the same effect has also been observed in ethylene-propylene copolymers [6, 7]). It might be argued that at the lamella surface there is strain and an increase of the unit cell size. Then it can be asked whether the lattice of the copolymer is larger not because of inclusion of perfluoromethyl groups but because the lamella surfaces are more numerous and therefore exert a stronger influence on cell size.

This article presents data and analyses as evidence that the larger separation of the axes in the copolymer is a result of inclusion of the perfluoromethyl groups in the crystals and not an artifact associated

\footnotetext{
* Abstract in Bull Am Phys. Soc 10, 354 (1965); NBS Tech. Note 236, 56 (1963); and NBS Tech. Note 260, 47 (1965)

1 Figures in brackets indicate the literature references at the end of this paper.
}

with transition temperature or lamella thickness. Also presented are data and analyses concerning the density, lamella thickness, and unit cell dimension of tetrafluoroethylene-hexafluoropropylene and ethylene-propylene copolymers. These indicate that the thinner lamellas of the copolymers rather than "amorphous defects" of reduced density around the methyl [8] or perfluoromethyl groups are primarily responsible for the reduction in density from that of the homopolymer.

\section{Experimental Procedures}

Wide angle $x$-ray diffraction measurements were made as a function of temperature using $\mathrm{Cu}$ radiation filtered by $\mathrm{Ni}$ and a cryostat that provided temperature control in the range 4 to $300^{\circ} \mathrm{K}[9,10]$. The present measurements for polytetrafluoroethylene and a copolymer similar to the intermediate one of reference [1] were made above to $80^{\circ} \mathrm{K}$ only, since this temperature was found to be well below the transition temperature. Measurements were made at approximately $10 \mathrm{deg}$ intervals with increasing temperature and a wait of about 50 min at each temperature. In the temperature range of the transition, the temperature intervals were shortened to $5 \mathrm{deg}$ with a wait of $40 \mathrm{~min}$. Temperatures were measured with a Au-2.1 percent $\mathrm{Co}$ versus $\mathrm{Cu}$ thermocouple [9] and are subject to an uncertainty of about $1 \mathrm{deg}$.

Since the polymers, especially the copolymer, did not yield suitable diffraction at large angles, they could not be used to aline the goniometer [11]. Therefore, silicon which had been measured previously [11] was pressed into asperities on the front surface of the polymer and diffraction from the $\{111\}$, $\{220\},\{311\},\{400\},\{331\},\{511\}$, and $\{440\}$ planes 
was used to aline that surface. ${ }^{2}$ Because the surface responded to contraction of both the sample, which was about $1 \mathrm{~mm}$ thick, and the apparatus, alinement was carried out at the low est temperature after $2 \mathrm{hr}$ were allowed for the attainment of thermal equilibrium. Subsequently, the alinement was checked at each temperature using diffraction from only the first planes above, and more were used only if realinement was necessary. Over the present temperature range, the expansion of silicon is very small, corresponding to a total change of less than $2 \times 10^{-3} \mathrm{~A}$ in the dimension of the unit cell [12].

Because of beam penetration into the sample, alinement of the front surface yields a small error in the determined spacings and a very small correction was made for this effect. However, comparison of the spacings determined for the two samples is not altered significantly by omission of this correction for the following reasons: the effect is small, measurements for the two samples were made in the same angular range, the difference in density of the two samples is about 5 percent only, and the variation of density over the temperature range of interest is about 5 percent only [13]. There are other sources of possible error, and the determined spacings are subject to an estimated uncertainty of about $0.02 \AA$. Most of this uncertainty is the result of systematic errors and because of similarity of the samples and the experimental procedures for each, is also not relevant to a comparison of the results for each. In order to minimize unwanted surface orientation effects [14], the samples were cooled slowly from the melt. Orientation in the surface layers of the samples was examined by x-ray diffraction with a Norelco micro camera and a $100-\mu$ beam of $\mathrm{Cu}$ radiation filtered by Ni. Transverse sections were cut from the samples and diffraction patterns were obtained with the beam parallel to the surface and incident upon the top 50 to $100 \mu$ of surface.

Wide-angle $x$-ray diffraction measurements were made at about $296^{\circ} \mathrm{K}$ as a function of comonomer concentration and lamella thickness with a Norelco diffractometer and $\mathrm{Cu}$ radiation filtered by $\mathrm{Ni}$. Samples about $0.3 \mathrm{~mm}$ thick were carefully placed at the same position in the same sample holder and at the same position in the diffractometer. With the slowest speed of the diffractometer and four recordings for each of the one to three positionings of each sample, this procedure yields average angles of the diffraction maxima which are subject to standard deviations corresponding to less than $2 \times 10^{-3} \AA$ in the unit cell dimension. This value is small enough that, together with the small differences in densities and in angles of the diffraction maxima of the different samples, it permits comparative measurements for the samples without use of an internal standard. The validity of this technique is supported by the fact that for two of the samples, the difference between the cell dimensions was reproduced with a powder camera. Similarly, the differ-

2 The silicon had initially been placed on the front surface with a silicone grease. The pressing technique was used after it was observed that the grease erystallized at about $230^{\circ} \mathrm{K}$. ence between cell dimensions of two other samples did not differ significantly from that measured by the technique described in the previous paragraph.

Samples with comonomer concentrations of approximately $0,3,4,5.75,6.2,7,7.6$, and $8 \mathrm{CF}_{3}$ units per 100 main chain carbon atoms were used. Lamella thickness was varied by isothermal crystallization for about one week at different supercoolings follow ed by slow cooling. Thinner lamellas were produced by quenching thin films of melt in ice water. Lamella thickness was measured with $\mathrm{Cu}$ radiation and a small-angle diffractometer.

\section{Results and Discussion}

A number of papers have discussed various aspects of the crystal structure of polytetrafluoroethylene $[3,5,15-19]$. With the present sample, diffraction from more than five $(h k 0)$ planes could be observed in addition to that from several other planes at all temperatures. When the separation of the molecular axes (cell dimension $a$ ) was determined from each of the various $h k 0$ reflections at $327^{\circ} \mathrm{K}$, there were small variations which were probably contributed to by variations in both the background of the scattering curve and the beam penetration of the sample with angle. These variations were not large enough to hamper comparisons with the copolymer and the 100 reflection was selected for comparison since it was the strongest of the $h k 0$ reflections that could be observed readily in the copolymer. At temperatures below the transition temperature, the lateral packing of the molecules is not quite hexagonal [19] and an average of the nearest neighbor distances is given.

Data for intermolecular distance, which are presented in figure 1, show a transition to occur at about $225^{\circ} \mathrm{K}$ in the copolymer. The scatter of the data gives a measure of the reproducibility and may be sufficient to mask the small [19] transition that occurs near $305^{\circ} \mathrm{K}$ in polytetrafluoroethylene. Below $225^{\circ} \mathrm{K}$, as well as above, the spacing of the molecular axes in the copolymer is larger than in polytetrafluoroethylene. ${ }^{3}$ The difference increases slightly at $225^{\circ} \mathrm{K}$ and above but the increase is only a small portion of the total difference for two reasons. First, the increase in spacing at the transition is not too great. Second, the difference between the average values of the expansion above and below the transition is only about $1.2 \times 10^{-4} \AA /{ }^{\circ} \mathrm{K}$. Thus, it seems reasonable to conclude that the larger separation of the molecular axes in the copolymer is real and that the answer to the first question raised in the introduction is negative. That is, at $296^{\circ} \mathrm{K}$, the greater part of the increase of separation of the axes in the copolymer is not an anomaly associated with transition temperature.

Variation of intermolecular distance with comonomer concentration is shown in more detail in figure 2 .

${ }^{3}$ Only a few data were taken with polytetrafluoroethylene for purposes of comparison here since precise measurements have been published [19]. The present results for $298^{\circ} \mathrm{K}$ do agree with these but there does not seem to be any reason to expect exact agreement in the range of the transitions which varies with rate of heating, polymer sample, etc. $[4,13]$. 


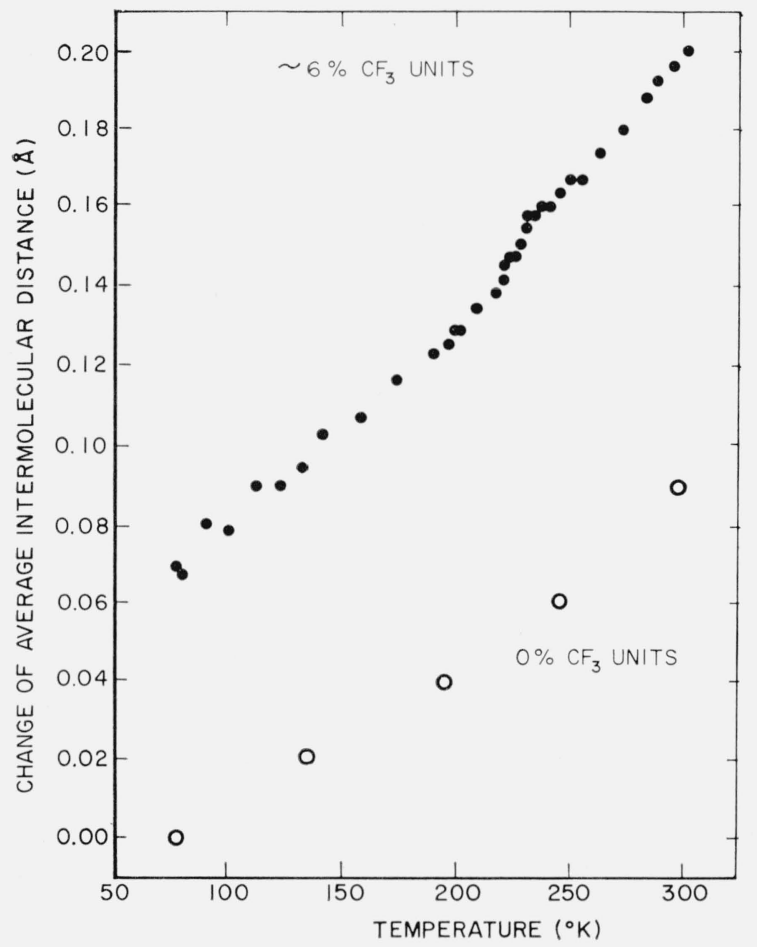

Figure 1. Temperature dependence of the change of average intermolecular distance with respect to an arbitrary reference.

The solid points represent a copolymer of tetrafluoroethylene and hexafluoropropylene with about six perfluoromethyl groups per 100 main-chain carbon atoms. The copolymer exhibits a phase change near $225^{\circ} \mathrm{K}$. Open points represent polytetrafluoroethylene.

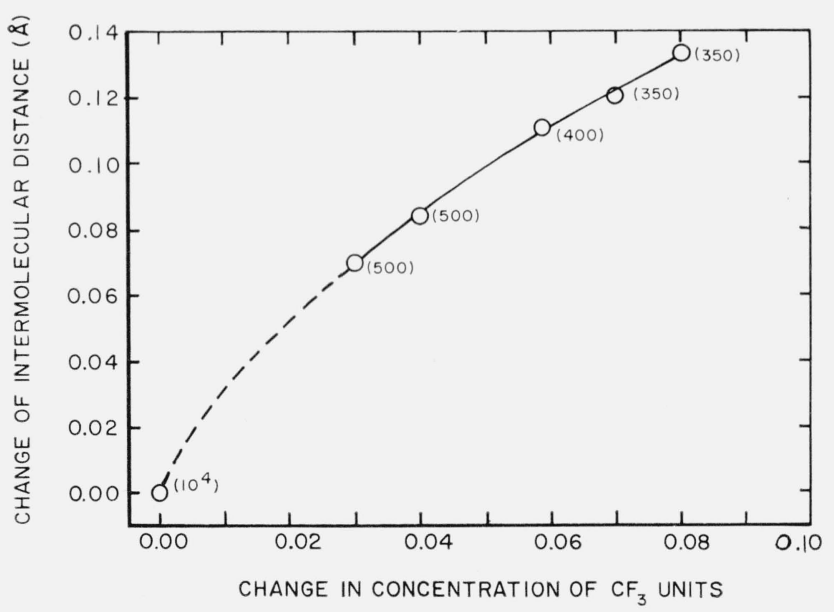

Figure 2. Change of intermolecular distance with the ratio of perfluoromethyl groups to main-chain carbon atoms (concentration).

The reference point is polytetrafluoroethylene at about $296^{\circ} \mathrm{K}$. The numbers in brackets give the approximate lamella thickness for each sample.

Between the samples with 0 and 3 perfluoromethyl units per hundred main chain atoms, there is a dotted line which is intended to guide the eye rather than represent the detailed variation of intermolecular distance. As noted above, part of this variation $(\sim 0.013 \stackrel{\mathrm{A}}{)})$ is a consequence of the fact that at about $296^{\circ} \mathrm{K}$, poly tetrafluoroethylene is not completely above the transitions [19] whereas the copolymer is. In the range of perfluoromethyl concentration between 3 and 8 percent, the intermolecular distance increases approximately uniformly with concentration at an average rate of about $1.4 \times 10^{-2} \AA$ per 1 percent change in concentration. The intermolecular distance in the copolymer is evidently not the same as that in the homopolymer as has been reported [2].

On figure 2 the approximate lamella thickness is given next to each point. These show the basis of the possibility that the variation of intermolecular distance with concentration might be caused by the variation of lamella thickness. However, as figure 3 shows for two concentrations of perfluoromethyl groups, when thickness is varied at constant concentration, there is little discernible variation of intermolecular distance for a thickness variation of about $200 \AA$. (The latter is greater than the variation of thickness when concentration varies from 0.03 to 0.08, cf. fig. 2.) This conclusion is supported by statistical analysis which yields a rate of change of intermolecular distance with thickness of $-2 \times 10^{-6} \AA / \AA$ with a standard deviation of $1.2 \times 10^{-5} \AA / \AA$. Therefore, it is concluded that the answer to the second question in the introduction is negative. That is, the greater part of the change of intermolecular distance with comonomer concentration is not a consequence of the change of lamella thickness. $^{4}$

On the basis of the results in the last two paragraphs, it is concluded that the increase of intermolecular distance with concentration of perfluoromethyl groups is primarily the consequence of inclusion of the groups within the crystals. This concept is supported by an aspect of the data other than the increase of cell dimension; that is, the diffuse nature of the diffraction from certain planes. The $107,108,1,0,15$, and $0,0,15$ reflections could be

${ }_{4}$ Although 99 percent confidence limits on the change of intermolecular distance with lamella thickness are somewhat larger, they are too small to invalidate the conclusion just made. We wish to note also that for both copolymers the three samples with thickest lamellas exhibited a trend toward increasing spacing with decreasing lamella thickness. Although this trend is too small to be considered significant in our data, it tends to be reproducible. Also, it is always vitiated by the data for the quenched (thinnest lamellas) samples. Such a trend could result from a number of possible causes ranging from artifact to real physical effect and they have not been pursued.

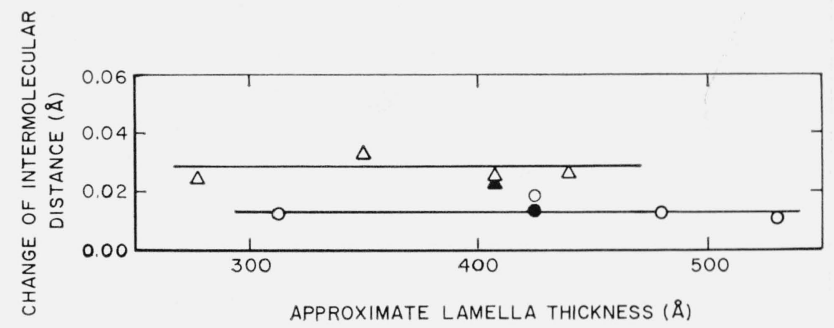

FIGURE 3. Change of intermolecular distance with approximate lamella thickness for samples with two different concentrations of perfluoromethyl groups (upper curve 0.076, lower curve 0.062).

The reference is $0.10 \AA$ on fig. 2 and the data were obtained at $296^{\circ} \mathrm{K}$. Data represented by open points were obtained with a diffractometer and the data represented by the solid points were obtained with a powder camera. 


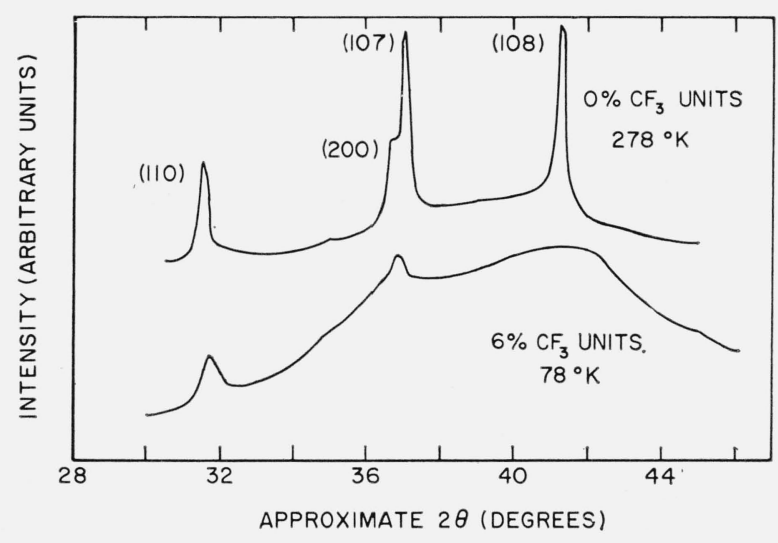

FIGURE 4. Intensity in arhitrary units as a function of approximate diffraction angle (20) for polytetrafluoroethylene at $278{ }^{\circ} \mathrm{K}$ and for a copolymer at $78{ }^{\circ} \mathrm{K}$.

These are the same samples as in figure 1. The curve for polytetrafluoroethylene has been arbitrarily displaced to higher intensities.

observed readily in polytetrafluoroethylene at room temperature but the corresponding ones were very broad and diffuse in the copolymer. Even at the lowest experimental temperatures, these reflections (or the corresponding ones below the transition temperature) remain diffuse as shown in figure 4. While this effect can be the consequence of surface orientation in quenched samples [14], wide angle $\mathrm{x}$-ray diffraction shows that this is probably not the case in the present, slowly cooled sample. As shown in figure 5, patterns obtained with the beam parallel to the surface and intercepting the top 50 to $100 \mu$ of surface show little preferential orientation. While the absence of orientation is difficult to confirm positively, patterns similar to figure 5 were
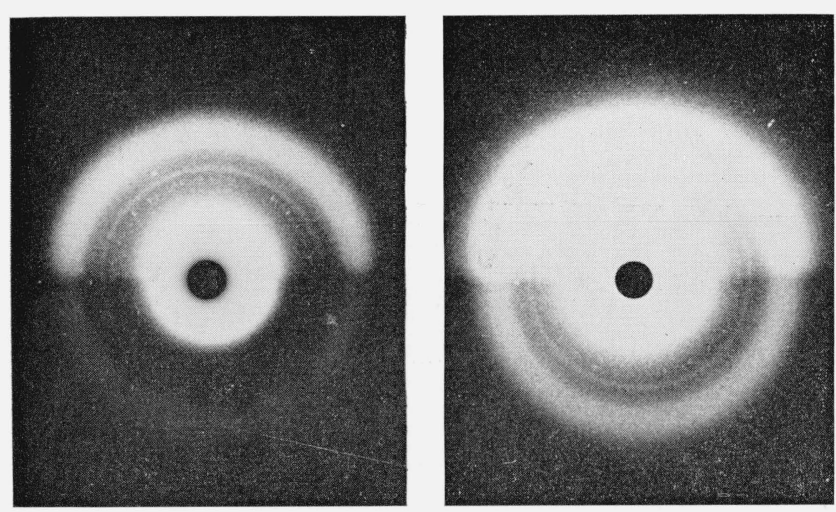

FiguRE 5. Diffraction pattern obtained with the x-ray beam parallel to the surface and incident upon the top 50 to $100 \mu$ of surface of the copolymer sample in figure 1.

The beam of $\mathrm{Cu} K_{\alpha}$ radiation is $100-\mu$ in diameter. Because the beam is near the horizontal surface, radiation diffracted upward encounters a different pathlength (and absorption) than that diffracted downward. Therefore, one-hal of the film is more strongly exposed than the other and two prints are presented in order to show the equivalence of the essential details in each half. obtained with several geometries of beam and sample. Also, one long exposure did not show orientation in the diffuse $0,0,15$ reflection.

Another possible cause of the effect is disorder. Although a certain amount of caution must be exercised in interpreting the present limited number of reflections (especially those with $l=15$ since they are intrinsically weak [19]), some observations can be made. For example, for $l=15$ (or 13 at low temperature) the reflections are governed by a zero-order Bessel function and therefore diffuseness would not result from rotational disorder about the chain axis but would result from disorder along the axis [17, 19]. Longitudinal disorder would probably be the cause of diffuseness for $l=7$ and 8 (or 6 and 7 ) but since these reflections are governed by a first-order Bessel function, diffuseness could result from rotational disorder. Thus, subject to the caution above, the diffuse nature of the reflections suggests longitudinal disorder along and possibly rotational disorder about the chain axis. Small disordering in rotation and translation might be expected from inclusion of the perfluoromethyl groups within the crystals. ${ }^{5}$

The density of the copolymers in figure 2 ranged from 2.155 to $2.133 \mathrm{~g} / \mathrm{cm}^{3}$ at $296^{\circ} \mathrm{K}$. These are smaller than typical homopolymer values which can be greater than $2.22 \mathrm{~g} / \mathrm{cm}^{3}$. However, it would be incorrect to assume that lamella thickness is largely independent of copolymer concentration and then to attribute lowering of the density directly to reduced density [8] around the comonomer units without first considering the known tendency for lamella thickness to decrease with increasing comonomer content [1, 6, 7]. Since mispacking of the folds of adjacent lamellas lowers the gross density $[20,21]$, copolymers should be less dense than the homopolymer simply because lamellas of the latter are often an order of magnitude thicker than the 350 to $500 \AA$ lamellas of the copolymers in figure 2 [22]. However, greater supercooling of the polytetrafluoroethylene melt produces samples with thinner lamellas. Data obtained by electron microscopy indicate that such samples with densities somewhat less than $2.18 \mathrm{~g} / \mathrm{cm}^{3}$ would have lamellas less than $500 \AA$ thick [23]. Also, light scattering yielded a structural dimension of $260 \AA$ for a sample with density of $2.13 \mathrm{~g} / \mathrm{cm}^{3}$ [24].

These densities are in the range of those for copolymers with similar lamella thickness. Therefore, to provide a more direct comparison and avoid systematic differences in thickness and density as determined by different techniques, a quenched sample of polytetrafluoroethylene was prepared and measured by the present techniques. This yielded a sample with lamella thickness of 550 to $600 \AA$ and density of $2.139 \mathrm{~g} / \mathrm{cm}^{3}$ which is less than the values of 2.151 and 2.155 for the copolymer samples with

\footnotetext{
5 This type of disordering cannot be adequately described by the word
} amorphous which implies liquid-like disorder. 
the $500 \AA$ lamellas. Reduced lamella thickness of the copolymer apparently accounts for the usual reduction of density. In fact, the data indicate that for copolymer and homopolymer samples with lamellas of equal thickness, the copolymer would be more dense.

Consideration of the increase of mass associated with the comonomer units together with the increase of cell volume suggests that the density of the lamellas is increased slightly by the comonomer units. $^{6}$ This type of analysis is based upon results from calculations for point and slightly larger centers of dilation in an elastic continuum [25-27] After introduction of the defects, the fractional dilations of the macroscopic and cell volumes are equal if no new substitutional sites are introduced. Experimental verification of the effect has been obtained for a number of examples in atomic solids $[26,28,29]$. While the present analysis may be subject to errors, the increase of lamella density would remove almost completely the discrepancy noted above for the density of copolymer and homopolymer samples with similar lamella thickness.

It can be argued that each case must be considered separately and therefore it is of interest that the available data indicate that the same effects occur in copolymers of ethylene and propylene. For slowly cooled samples, the measured density decreases ca. $8 \times 10^{-3} \mathrm{~g} / \mathrm{cm}^{3}$ for each methyl group per 100 main chain atoms [8]. Slowly cooled copolymers with methyl group concentrations between 0 and 1.5 percent exhibit a decrease of lamella thickness of about $55 \AA$ for each percent of methyl groups [6]. ${ }^{7}$ Together with the variation of density of the homopolymer with lamella thickness [20] these data yield a calculated decrease of ca. $10 \times 10^{-3} \mathrm{~g} / \mathrm{cm}^{3}$ for each percent of methyl groups. While all these data were not available for a coherent set of samples as were the data presented above for the fluorocarbons, the density decrease calculated from lamella thickness again appears to be greater than that actually observed. However, taking the data for cell dimension and comonomer concentration given in reference [8] and calculating the density of the lamellas again removes most of the discrepancy.

The decrease of density of both copolymer series is apparently a result primarily of decreasing lamella thickness and not of reduced density around the comonomer units. Indeed, lamella density based on comonomer concentration and cell size is increased by the comonomer units and this result tends to agree with the experimental data. However, this latter fact cannot be established unambiguously without a rather formidable set of very accurate measurements of density, unit cell, and lamella thickness on a series of copolymer samples which have accurately known, different comonomer concentrations and which have been isothermally

\footnotetext{
6 The concentration of perfluoromethyl groups in the lamellas is taken as that 6 The concentration
in the whole polymer.

$n$ the whole polymer. 7 Although data over a wider range of concentration are available, they have been obtained on samples which were not slowly cooled. These show the same general trend in lamella thickness with the rate of decrease becoming smaller at higher concentrations.
}

crystallized at different supercoolings. In any event, there are no data for small scale techniques which unambiguously indicate extensive amorphous disorder around the methyl groups and so gross a measurement as density is a poor one to use in the resolution of small scale structural details such as the nature of the disorder around the groups.

\section{Conclusions}

Measurements of the separation of molecular axes have been made as a function of comonomer concentration, temperature and lamella thickness in copolymers of tetrafluoroethylene and hexafluoropropylene. These give evidence that the increase of separation with concentration is primarily the consequence of inclusion of the perfluoromethyl groups in the crystals. This conclusion is supported by the fact that the diffuseness of some of the x-ray reflections in the copolymers indicates the presence of molecular disorder which might be expected from inclusion of the perfluoromethyl groups in the crystals. The density of the copolymers is lower than that of the homopolymer primarily because the former have thinner lamellas and not because of "amorphous defects" of lower density around the perfluoromethyl groups. The same statement applies to copolymers of ethylene and propylene at low methyl group concentrations. For both copolymer series, the density of the lamellas is apparently increased by the inclusion of the methyl groups in the crystals as defects.

The authors express their thanks to W. A. Zisman and Marianne K. Bernett of the U.S. Naval Research Laboratory for providing samples of copolymers. Also, they want to thank E. S. Clark of the DuPont Experimental Station and J. P. Colson and their other colleagues at the National Bureau of Standards for helpful discussions and encouragement. Helpful discussions with Professor R. W. Balluffi are gratefully acknowledged.

\section{References}

[1] R. K. Eby, J. Res. NBS 68A (Phys. and Chem.) No. 3, 269 (1964).

[2] H. G. Killian, Kolloid-Z. 176, 49 (1961).

[3] C. W. Bunn and E. R. Howells, Nature 174, 549 (1954).

[4] F. A. Quinn, D. E. Roberts, and R. N. Work, J. Appl. Phys. 22, 1084 (1951).

[5] H. A. Rigby and C. W. Bunn, Nature 164, 583 (1949).

[6] H. Hendus, Ergeb. Exakt. Naturw. 31, 331 (1959).

[7] C. Sella, Compt. Rend. 248, 1819 (1959).

[8] B. Wunderlich and D. Poland, J. Polymer Sci. 1A, 357 (1963).

[9] A. Black, L. H. Bolz, F. P. Brooks, F. A. Mauer, and H. S. Peiser, J. Res. NBS 61, No. 5, 367 (1958) Rp2907.

[10] F. A. Mauer and L. H. Bolz, J. Res. NBS 65C (Engr. and Instr.) No. 4, 225 (1961).

[11] F. A. Mauer and L. H. Bolz, WADC Technical Report 55-473, December 1955.

[12] S. I. Novikova and P. G. Strelkov, Soviet Phys.-Solid State 1, 1687 (1959)

[13] R. K. Kirby, J. Research NBS 5\%, 91 (1956) Rp2696. also I. E. Leksina and S. I. Novikova, Soviet Phys.Solid State 1, 453 (1959). 
[14] E. S. Clark and H. W. Starkweather, Jr., J. Appl. Polymer Sci. 6, 541 (1962).

[15] R. H. H. Pierce, Jr., E. S. Clark, J. F. Whitney, and W. M. D. Bryant, presented at the 130th meeting of the American Chemical Society, Atlantic City, N.J., September 1956.

[16] G. Butenuth, Verhandlungsberichte der Kolloid Gesellschaft 18, 168 (1958).

[17] E. S. Clark and L. T. Muus, Z. f. Kristallographie 11\%, 2/3, 109 (1962).

[18] A review is presented by C. A. Sperati and H. W. Starkweather, Jr., Fortschr. Hochpolymer. Forsch. 2, 465 (1961).

[19] E. S. Clark and L. T. Muus, Z. f. Kristallographie 11\%, 2/3, 119 (1962)

[20] R. G. Brown and R. K. Eby, J. Appl. Phys. 35, 1156 (1964).

[21] E. W. Fischer and G. F. Schmidt, Angew. Chem. Intern. Ed. Engl. 1, 488 (1962).
[22] C. W. Bunn, A. J. Cobbold, and R. P. Palmer, J. Polymer Sci. 28, (1958).

[23] H. W. Starkweather, Jr., SPE Transactions 3, 57 (1963).

24] H. W Starkweather, Jr., J. Polymer Sci. 2B, 499 (1964).

[25] J. D. Eshelby, J. Appl. Phys. 25, 255 (1954); Proc. Royal Soc. London, 142A, 376 (1957); and Solid State Physics 3, 79 (1956). See also, K. Huang, Proc. Roy. Soc. (London) A190, 102 (1947).

[26] R. O. Simmons and R. W. Balluffi, J. Appl. Phys. 30, 1249 (1959).

[27] R. W. Balluffi and R. O. Simmons, J. Appl. Phys. 31, 2284 (1960)

[28] J.A. Bearden, Phys. Rev. 13\%, B181 (1965).

[29] Francisco Eiichi Fujita and Ulrich Gonser, J. Phys. Soc. Japan 13, 1068 (1958).

(Paper 69A5-369) 


\section{Publications of the National Bureau of Standards*}

\section{Selected Abstracts}

Improved ten-picofarad fused silica dielectric capacitor, R. D. Cutkosky and L. H. Lee, J. Res. NBS 69C (Engr. and Instr.), No. 3, 173-179 (July-Sept. 1965). \$0.75

Some defects in a set of fused silica dielectric capacitors constructed in 1961 are listed, and methods for their reduction or elimination are described. The construction of a new set of capacitors completed in 1964 is described in detail. Preliminary stability data presented indicates that the typical drift of the 1964 capacitors with respect to their mean was less than two parts in $10^{7}$ in five months.

Equipment for single-crystal growth from the melt suitable for substances with a low melting point, A. T. Horton and A. R. Glasgow, J. Res. NBS 69C (Engr. and instr.), No. 3, 195-198 (July-Sept. 1965). \$0.75

Glass apparatus is described for the purification and growth of crystals with melting points up to about $130{ }^{\circ} \mathrm{C}$ by a modified Bridgman technique. The temperatures of the melt and the solid are maintained by two immiscible liquids at whose interface a sharp temperature drop exists. A sealed Pyrex tube containing the specimen is slowly lowered throuth the interface. The specimen is maintained under its own vapor pressure in contact only with the glass container. Provision is made for the removal of the last portions of the specimen to solidify from each of several successive recrystallizations.

The equipment has been found effective for the purification of trans-stilbene, dimethyl oxalate, benzoic acid and benzene. It could also be used for careful studies of thermal and radiation stability of pure substances.

Cartesian diver as a density comparator, H. A. Bowman and R. M. Schoonover, J. Res NBS 69C (Engr. and Instr.), No. 3, 217-223 (July-Sept. 1965). \$0.75

This report describes a hydrostatic weighing system which provides values of apparent mass in water reproducible (standard deviation) between independent measurements of about 0.2 microgram. The definition of "independent" used here, includes the requirement that the sample under observation be removed from the water, dried, and recleaned between measurements. This precision is between one and two orders better than existing hydrostatic balances, and permits high quality density measurements without recourse to large sample sizes. The system is used as a comparator, hence the absolute accuracy of results can be no better than that of the standards used. Typical data are presented which were taken during experiments on 2-gram pieces of single crystal silicon, and the standard deviation in density of an independent observation was computed to be $2: 10^{7}$.

The system is particularly well suited to detection of slight density changes in small size samples. In this service, it is not subject to the requirement for high accuracy standards. Data are reported on density changes of about $5: 10^{5}$ which occurred in a 250 milligram ceramic crystal. Two independent observations reported this change to agreement of about $71 / 2$ percent.

Cryogenic behavior of selected magnetic materials, J. J. Gniewek and E. Ploge, J. Res. NBS 69C (Engr. and Instr.), No. 3, 225-236 (July-Sept. 1965). \$0.75

Measurements of a-c core loss and d-c magnetic properties including coercive force, remanence and hysteresis loss are reported at temperatures of $273,195,76$, and $4{ }^{\circ} \mathrm{K}$ for a variety of commercial magnetic Fe-Si and $\mathrm{Fe}-48$ percent $\mathrm{Ni}$ allovs. Of the materials tested the high silicon content $(3-4.45 \% \mathrm{Si}) \mathrm{Fe}-\mathrm{Si}$ alloys were found to be the least temperature sensitive. Hysteresis loss increases between 273 and $4{ }^{\circ} \mathrm{K}$ of up to 100 percent were measured for the iron-nickel materials.
Effects of rocket outgassing on rf experiments, W. Pfister and J. C. Ulwick, Radio Sci. J. Res. NBS/USNC-URSI 69D, No. 9, 1219-1225 (September 1965). \$1.00

Peculiarities in the results of electron density measurements with rockets were noticed on several occasions. They were found to be effects of rocket outgassing. When the fuel valves of Aerobee rockets are not shut after burnout, residual fuel leaks out and diffuses into the atmosphere. Electrons attach to the fuel and decrease in concentration while the positive ions are not affected. Outgassing effects were observed on probe experiments flown in rockets as well as on propagation experiments between rocket and ground. Quantitative estimates indicate that the leaking fuel is a very effective attaching agent. Some solid fuel rockets also show similar effects.

Magneto-ionic propagation in inhomogeneous media. Part I. Transverse propagation, B. K. Banerjea, Radio Sci. J. Res. NBS/USNC-URSI 69D, No. 9, 1285-1295 (September 1965). $\$ 1.00$

Propagation of electromagnetic waves in an inhomogeneous magneto-ionic medium has been discussed with special reference to ionospheric propagation. This involves the study of two coupled linear second-order differential equations with coefficients having one essential and more than one regular singularity. The problem has been tackled in two stages divided into Parts $I$ and II of this paper.

In Part I, dealing with the transverse propagation in a parabolic electron-layer, the wave-equation, belonging to a class higher than the confluent hypergeometric or Mathieu equations, has been investigated. In Part II, dealing with the oblique propagation, the effect of the coupling function for the above class of equations has been studied, and relevant asymptotic solutions for the coupled equations derived.

Mathematical expressions for the physical observables in ionospheric investigations have been derived from the solutions of the wave-equations inside a parabolic electron-layer.

Magneto-ionic propagation in inhomogeneous media. Part II. Oblique propagation, B. K. Banerjea, Radio Sci. J. Res. NBS/USNC-URSI, 69D, No. 9, 1297-1306 (September 1965). $\$ 1.00$

Oblique propagation of electromagnetic waves in an inhomogeneous magneto-ionic medium is described by a pair of coupled, linear, second-order differential equations, with coefficient functions having one essential singularity and more than one pole. An analytic method to study this general type of propagation has been developed in this paper.

Mathematical expressions for all the physical observables in the inospheric investigations have been derived for a parabolic electron-layer. The expressions for the phase-retardation and the tilt of the polarization ellipse differ radically from those derived from the ray-optics of Appleton and Hartree.

Automatic indexing: A state-of-the-art report, M. E. Stevens, NBS Mono. 91 (Mar. 30, 1965), \$1.50.

A state-of-the-art survey of automatic indexing systems and experiments has been conducted by the Research Information Center and Advisory Service on Information Processing, Information Technology Division, Institute for Applied Technology, National Bureau of Standards. Consideration is first given to indexes compiled by or with the aid of machines, including citation indexes. Automatic derivative indexing is exemplified by key-word-in-context (KWIC) and other word-in-context techniques. Advantages, disadvantages, and possibilities for modification and improvement are discussed. Experiments in automatic assignment indexing are summarized. Related research efforts in such areas as automatic classification and categorization, computer use of thesauri, statistical association techniques, and linguistic data processing are described. A major question is that of evaluation, 
particularly in view of evidence of human inter-indexer inconsistency. It is concluded that indexes based on words extracted from text are practical for many purposes today, and that automatic assignment indexing and classification experiments show promise for future progress.

The examination of weighing equipment, M. W. Jensen and R. W. Smith, NBS Handbook 94 (Mar. 1, 1965), \$3.00. (Supersedes H3\%).

This Handbook is primarily directed to the presentation of a coordinated series of step-by-step Examination Procedure Outlines (EPO's) for weigning equipment, recommended for adoption and use, as minimal requirements, by weights and measures agencies, commercial service agencies, weighing equipment owners and operators, and manufacturers of weighing devices. Supporting information embraces discussions on related topics such as reference and field standards report forms, tolerances, weighing principles, and element of scale construction and performance. Extensive weight and measures tables-basic, interrelation of units, and equivalents - and a list of references for further study are appended. An alphabetical index is supplied.

Standard Reference Materials: Accuracy of solution $x$-ray spectrometric analysis of copper-base alloys, $R$. Alvarez and R. Flitsch, NBS Misc. Publ. 260-5 (Mar. 15, 1965), 25 cents. $\mathrm{X}$-ray fluorescence spectrometry has been investigated as an independent method for the analysis of certain major constituents in NBS standard reference materials. The determination of copper and zinc in cartridge and aluminum brass samples which were to be certified as standard materials, was selected for study. After a preliminary analysis, a solution of the unknown and a closely-matched synthetic standard were compared without the use of an internal standard or added control element. To achieve reliable results, close control of the type and concentration of acid was found necessary, and, for cells employing films as windows, the position of the film was critical. The temperature rise of the cell during irradiation was $0.1{ }^{\circ} \mathrm{C}$, which did not contribute significantly to error. Typical coefficients of variation obtained for individual results in a group of 8 runs were $0.3 \%$ for copper and $0.4 \%$ for zinc. The agreement between chemical and $\mathrm{x}$-ray results was within $0.3 \%$ of the amount present for both elements.

Thermal properties of aqueous uni-univalent electrolytes, V. B. Parker, NSRDS-NBS2, (Apr. 1, 1965), 45 cents.

The available specific heat, heat of dilution, and heat of solution data for aqueous solutions of uni-univalent electrolytes have been critically reviewed and tables of selected "best" values at $25{ }^{\circ} \mathrm{C}$ prepared. In addition, the neutralization data have been critically reviewed in order to obtain the "best" value, $13,345 \mathrm{cal} / \mathrm{mole}$, for the heat of ionization of water at $25^{\circ} \mathrm{C}$.

The electrolytes reviewed include the hydroxides, halides and oxyhalides, nitrates and nitrites, formates and acetates, cyanides, cyanates and thiocyanates, and permanganates of hydrogen, ammonium and the methyl ammonium derivatives, silver, and the alkali metals.

Optical scintillation; a survey of the literature, J. R. MeyerArendt and C. B. Emmanuel, NBS Tech. Note 225 (Apr. 5 , 1965), 70 cents.

In this Technical Note, main emphasis is placed on providing the rader with an exhaustive survey of the literature, covering the field of effects of atmospheric refraction on the propagation of electromagnetic radiation at optical frequencies.

One may distinguish systematic, regular, or normal refraction on the one side from random refraction on the other. The former can be predicted theoretically, using various types of atmospheric models; the latter requires analysis by statistical methods.

Numerous observational, experimental, and theoretical aspects of random refraction, that is, of scintillation in its widest sense, are discussed. The following topics are dealt with: refraction in plane and in spherically stratified media, refractive index variations, radio refraction, scintillation as a function of aperture size, zenith distance, site location, dispersion, and meteorological conditions, the frequency spec- trum of scintillation, terrestrial scintillation, image distor tion and contrast reduction, refraction and diffraction theories of scintillation, autocorrelation analyses, radio star scintillation, and coherence problems. Questions of atmospheric scattering, absorption, and depolarization are excluded. Finally, a brief review is given concerning newer experimental methods for the observation, recording, and analysis of optical scintillation, including suggestions as to what further theoretical and experimental efforts should be undertaken.

A calorimetric determination of the enthalpy of graphite from 1200 to $2600{ }^{\circ} \mathbf{K}, \mathrm{E}$. D. West and S. Ishihara, (Proc. 3rd Symp. Thermal Physical Properties, Purdue Univ., Lafayette, Ind., Mar. 22-26, 1965), Book, Advances in Thermophysical Properties at Extreme Temperatures and Pressures, pp. 146151 (American Society of Mechanical Engineers, New York, N.Y., 1965).

Measurements are reported of the increase in the enthalpy of high-purity graphite between room temperature and 1200 to $2600{ }^{\circ} \mathrm{K}$. A new apparatus is described briefly. Methods of operation are developed which eliminate some systematic and random errors and are especially advantageous at high temperatures. The enthalpy data fit the equation

$H_{T}-H_{298.15}=28.9004 T-1.045 \times 10^{-4} T^{2}$

$-16,126.2 \log _{10} T / 313.15-8907.3$

where $H$ is in absolute joules per gram atomic weights and $T$ in degrees Kelvin.

A high-speed (milliseconds) method for the simultaneous measurement of enthalpy, specific heat, and resistivity of electrical conductors at high temperatures, A. Cezairliyan (Proc. Srd Symp. Thermophysical Properties, 1965), Book, Advances in Thermophysical Properties at Extreme Temperatures and Pressures, pp. 253-262(American Society of Mechanical Engineers, New York, N.Y., 1965).

A method for the simultaneous measurement of enthalpy, specific heat, and electrical resistivity of electrical conductors at high temperatures $\left(1000{ }^{\circ} \mathrm{K}\right.$ to the melting point of the sample) in experiments of short duration (milliseconds) is described. The rapid direct joulean heating is achieved by a single energy pulse obtained from a battery unit. The average heating rate was approximately $6600{ }^{\circ} \mathrm{K} \mathrm{sec}-1$. The sample is tubular in form with a small hole drilled through the call at the middle of its length to approximate black body conditions, thus allowing the measurement of transient true temperatures by photoeiectric methods. Results on molybdenum (from approximately 1300 to $1600^{\circ} \mathrm{K}$ ) are obtained and compared with available literature values.

Absolute measurement of $W$ for polonium-210 alpha particles in nitrogen, argon, and argon-methane mixture, $Z$. Bay and F. D. MeLernon, Radiation Res. 24, No. 1, 1-8 (Jan. 1965). Absolute values of $W_{\alpha}$ at the $\mathrm{Po}^{210}$ alpha energy have been measured by both the slow and fast charge collection methods in nitrogen, argon, and in a mixture of argon and ten percent methane. The full alpha energy was expended in a gridded ionization chamber. The ionization chamber's collection plate was directly connected to a vibrating reed electrometer and was capacitively connected to a fast pulse height measuring system. Pulse height calibration was achieved by charges from a pulser collected and measured in the same electrometer. The $W_{\alpha}$ values obtained in the fast measurements agree with previous values measured with the slow method. From the difference between the charges measured in the slow and fast methods an estimate of the recoil ionization could be made.

Atomic lifetimes in neon I, J. Z. Klose, Astrophys. J. 141, No. 2, 814-818 (Feb. 15, 1965).

Mean lives of several atomic levels in Neon I have been determined using a method of electronic excitation and delayed coincidence. Lifetimes of the following levels given in the Paschen notation are: $2 \mathrm{p}_{1}, 15.3 \pm 0.4$ nanoseconds; $2 \mathrm{p}_{2}, \quad 16.3+0.6 \mathrm{~ns} ; 2 \mathrm{p}_{5}, 40.7+1.8 \mathrm{~ns}$; and $4 \mathrm{~d}_{1}^{\prime}, 476 \pm 33 \mathrm{~ns}$. The errors given are probable errors in the measurement. The systematic errors assigned to the $2 p_{1}$ and $2 p_{2}$ levels are each $5 \%$ with the corresponding errors for the $2 \mathrm{p}_{5}$ and $4 \mathrm{~d}_{1}^{\prime}$ levels $50 \%$ each. 
Description and analysis of the third spectrum of cerium (Ce III), J. Sugar, J. Opt. Soc. Am. 55, No. 1, 33-58 (Jan. 1965).

New observations of the Ce III spectrum from $757 \AA$ to 11091 $\AA$ are given, including 1700 lines not previously reported. The ground level of the ion is established as the ${ }^{3} \mathrm{H}_{4}$ state of the $4 f^{2}$ electron configuration. One hundred twenty-six newly discovered energy levels are given. The ionization limit, at $161955 \mathrm{~cm}^{-1}$, is calculated from the three member 4 fnd series.

Effect of temperature on the vacuum ultraviolet transmittance of lithium fluoride, calcium floride, barium fluoride, and sapphire, A. H. Laufer, J. A. Pirog, and J. R. MeNesby, J. Opt. Soc. Am. 55, No. 1, 64-66 (Jan. 1965).

The effect of temperature on the vacuum ultraviolet transmission of $\mathrm{LiF}, \mathrm{CaF}_{2}, \mathrm{BaF}_{2}$, and sapphire has been measured. It is found that, at the short wave edge, the transmission curves shift to higher wavelengths as the temperature is raised. Thus, near the short wave cutoff, windows are rendered opaque with relatively modest increases in temperature. The importance of these observations to vacuum ultraviolet photochemistry and spectroscopy at elevated temperatures is discussed.

Elastic constant of single crystal $\mathrm{ThO}_{2}$ at $25{ }^{\circ} \mathrm{C}$, P. B. Macedo, W. Capps, and J. B. Wachtman, Jr., J. Am. Ceram. Soc. 4\%, No. 12, 651 (Dec. 1964).

The elastic constants of single crystal $\mathrm{ThO}_{2}$ at $25{ }^{\circ} \mathrm{C}$ were determined to be $c_{11}=3.67 \pm .04, \quad c_{12}=1.06 \pm .02$, and $c_{44}=$ $0.797 \pm .008$ in units of $10^{12} \mathrm{~d} / \mathrm{cm}^{2}$.

Electron density measurements in the magnetically confined arc, C. K. MeLane, S. Takeda, W. E. Thomas, Jr., and R. C. Thompson, J. Appl. Phys. 36, No. 2, 327-341 (Feb. 1965).

Three methods were used to obtain electron density as a function of radius in a magnetically confined, low pressure argon arc. The first utilized the phase shift of a reflected $.35 \mathrm{GHz}$ microwave, and the second determined density from the ion saturation current to a Langmuir probe. The third determination utilized the broadening of the $\mathrm{H} \beta$ line emitted by a small quantity of added hydrogen. Agreement among the three methods is satisfactory; the electron density at the axis of this discharge is of order $10^{14} \mathrm{~cm}^{-3}$ in agreement with results obtained by others for discharges of similar type.

Observation of the products of ionic collision processes and ion decomposition in a linear, pulsed time-of-flight mass spectrometer, R. E. Ferguson, K. E. MeCulloh, and H. M. Rosenstock, J. Chem. Phys. 42, No. 1, 100-106 (Jan. 1, 1965).

A retarding potential technique has been investigated which permits study of secondary processes occurring after ion acceleration in a time-of-flight mass spectrometer. By application of a retarding field near the end of the flight path, peaks due to neutral species and fragment ions formed after acceleration are separated from their parent ion peaks and displayed in the same panoramic mass spectrum. Charge exchange, collision-induced dissociation, and spontaneous (metastable) ion decomposition are easily observed. The identities of initial ions and fragment ions involved in secondary processes can be determined unambiguously without complications of peak overlap.

Oscillator strengths for lines of $\mathrm{Fe} \mathrm{I}$ between 2500 and $3200 \mathrm{~A}$, R. B. King, K. H. Olsen, and C. H. Corliss, Astrophys. J. 141, No. 2, 354-363 (Feb. 15, 1965).

Measurements of total absorption have been made for lines of Fe I excited in a graphite tube furnace operated at various temperatúres between 1600 and $3000^{\circ} \mathrm{K}$. Oscillator strengths derived from them are reported for 300 lines between 2500 and $3200 \mathrm{~A}$.

Direct and inert-gas-sensitized radiolysis and photolysis of methane in the solid phase, P. Ausloos, R. E. Rebbert, and S. G. Lias, J. Chem. Phys. 42, No. 2, 540-548 (Jan. 15, 1965). The photolysis of $\mathrm{CH}_{4}-\mathrm{CD}_{4}$ mixtures has been briefly in- vestigated at $20^{\circ} \mathrm{K}$ using the xenon and krypton resonance lines. From the isotopic composition of the hydrogen and ethane fractions, it was shown that, in the solid phase, the excited methane molecule decomposes according to the following two modes:

$$
\begin{aligned}
& \text { 1. } \mathrm{CH}_{4} * \rightarrow \mathrm{CH}_{3}+\mathrm{H} \\
& \text { 2. } \mathrm{CH}_{4} * \rightarrow \mathrm{CH}_{2}+\mathrm{H}_{2}
\end{aligned}
$$

The methylene radical inserts into methane to form ethane $-d_{6},-d_{4},-d_{2}$, and $-d_{0}$. In the direct radiolysis of methane at $20{ }^{\circ} \mathrm{K}$ and $77^{\circ} \mathrm{K}$, the same processes may occur as in the photolysis. But, in addition, other bimolecular reactions, probably of the type

$$
\mathrm{CH}_{4}{ }^{+}+\mathrm{CH}_{4} \rightarrow \mathrm{CH}_{5}{ }^{+}+\mathrm{CH}_{3}
$$

have to be involved. When methane is irradiated in an argon matrix, however, elimination of a hydrogen molecule from methane becomes the major process. This is in strong contrast to the xenon-sensitized radiolysis in which case mainly hydrogen atoms and methyl radicals are formed. In the argon-, krypton-, and xenon-sensitized radiolysis, there is a gradual decrease in the efficiency of the energy transfer with increasing dilution. Radiolysis of $\mathrm{CD}_{4}-\mathrm{C}_{2} \mathrm{H}_{4}$ (1:0.01) mixtures indicated that, at $77^{\circ} \mathrm{K}$, hydrogen atoms react with ethylene and propylene to form higher saturated hydrocarbons while, at $20^{\circ} \mathrm{K}$, hydrogen atoms disappeared mainly by recombination with other free radicals.

Vapor phase growth kinetics of potassium and mercury crystals, R. L. Parker and S. C. Hardy, Book, Condensation and Evaporation of Solids, Proc. Symp. Condensation and Evaporation of Solids, pp. 649-664 (Gordon and Breech, New York, N.Y., Nov. 1964).

Results are presented regarding two types of experiment on the growth rates of single crystals of potassium and of mercury from supersaturated vapor; and some preliminary results on the evaporation of potassium crystals. In the first growth experiment, direct optical measurements of the growth rates of (110) faces of an equiaxed potassium crystal of $1 \mathrm{~mm}$ size, for low vapor supersaturations between 3.0 and 0.11 have given unit condensation coefficients. Comparison of this result with the Burton, Cabrera, and Frank theory is made. In the second type of growth experiment, results are presented on the growth kinetics of mercury and of potassium whiskers using Gomer's electron field emission technique. Many of the results on $\mathrm{Hg}$ whiskers agree with those obtained earlier by Gomer, including positive exponential length growth, orientation, terminal lengths, and surface diffusion coefficients. Some similar and some new features are observed on $\mathrm{K}$ whiskers; these represent the first use of an alkali metal as a field emitter, to the best of our knowledge. Finally, the evaporation of potassium whiskers at saturation ratios near unity is found to occur from the tip only, in rather the reverse process of growth; this result is of interest in connection with the role of crystal edges in evaporation.

Effect of electrical fields and density in the radiolysis of ethane, H. H. Carmichael, R. Gorden, Jr., and P. Ausloos, J. Chem. Phys. 42 No. 1, 343-351 (Jan. 1, 1965).

The gamma-ray radiolysis of $\mathrm{C}_{2} \mathrm{H}_{6}-\mathrm{C}_{2} \mathrm{D}_{6}-\mathrm{NO}$ and $\mathrm{CH}_{3} \mathrm{CD}_{3}-\mathrm{NO}$ mixtures has been investigated as a function of applied electrical field. In the saturation current region, a number of products resulting from the decomposition of neutral excited molecules increase about fivefold before the onset of secondary ionization while several other products, which can be ascribed to ion molecule reactions, remain essentially unchanged. The modes of decomposition of the excited ethane molecules formed by electron impact, as derived from the applied field experiments, are the same as those observed in the vacuum ultraviolet photolysis at $1470 \mathrm{~A}$ and at $1236 \mathrm{~A}$. From the isotopic composition of the products it could be deduced that the average energy transferred to ethane by electron impact is greater than $10 \mathrm{eV}$. A value of 0.5 was derived for the number of neutral excited molecule decompositions per ion pair.

A change in density has a pronounced effect on the product distribution, both in the photolysis at $1236 \mathrm{~A}$ and the radiolysis. In the radiolysis, several of the changes can be ascribed 
to the diminishing fragmentation of the parent ion with an increase in density. However, products resulting from the fragmentation of the neutral excited ethane molecules formed in the radiolysis also show a strong dependence on density because of collisional stabilization of the primary fragments and of the products formed in secondary reactions. For instance, the propane which could be entirely ascribed to the insertion reaction:

$$
\mathrm{CH}_{2}+\mathrm{C}_{2} \mathrm{H}_{6}+\mathrm{M} \rightarrow \mathrm{C}_{3} \mathrm{H}_{8}+\mathrm{M}
$$

increases with an increase in density in the photolysis as well as in the radiolysis.

Equilibrium pressures of oxygen over $\mathrm{MnO}_{2}-\mathrm{Mn}_{2} \mathrm{O}_{3}$ at various temperatures, E. M. Otto, J. Electrochem. Soc. 112, No. 4, 367-370 (Apr. 1965).

Oxygen pressures of the pyrolusite form of $\mathrm{MnO}_{2}$ have been determined in a temperature range of $441^{\circ}$ to $642{ }^{\circ} \mathrm{C}$. The dissociation reaction $4 \mathrm{MnO}_{2}(\mathrm{c})=2 \mathrm{Mn}_{2} \mathrm{O}_{3}(\mathrm{c})+\mathrm{O}_{2}(\mathrm{~g})$ has been found to reach a steady state in the forward direction. reaction in the reverse direction was exceedingly slow and did not reach a steady state.

$\triangle H^{\circ}$ and $\triangle S^{\circ}$ for the reaction at $813^{\circ} \mathrm{K}$ are $37.87 \mathrm{kcal} *$ and $51.28 \mathrm{cal} / \mathrm{deg}$, respectively. With little error these values can be used in the equation

$$
-4.5758 \log \mathrm{pO}_{2}(\mathrm{~atm})=37,870 / \mathrm{T}-51.28
$$

to calculate the pressure for any temperature in the above mentioned range. Conversion to $298.15^{\circ} \mathrm{K}$ resulted in $\triangle H^{\circ}{ }_{298}=38.8 \mathrm{kcal}$ and $\triangle S^{\circ}{ }_{298}=52.8 \mathrm{cal} / \mathrm{deg}$ for the dissociation. The limits of uncertainties are not given here because equilibria were not attained by recombination.

Direct observation of the optical anisotropy of the holmium nucleus, E. Ambler, E. G. Fuller, and H. Marshak, Phys Rev. 138, No. 1B, B117-B126 (Apr. 12, 1965).

The optical anisotropy of the holmium nucleus in the giant resonance energy region has been shown to exist by measuring the yield of photoneutrons as a function of the orientation of the nucleus with respect to a bremsstrahlung beam direction. The nuclei were aligned by the Bleaney method using a continuously operating $\mathrm{He}^{3}$ refrigerator to cool a single crystal of holmium ethyl sulfate to $0.29^{\circ} \mathrm{K}$. The orientation effects observed could be explained if the absorption cross section for holmium was made up primarily of a component given by the dynamic collective theory but which also included a small scalar component (about $15 \%$ of the total) which had no orientation effects associated with it. In fitting the data, a reanalysis of previous data on the holmium absorption cross section was made.

Interference patterns in reverberant sound fields. II, R. V. Waterhouse and R. K. Cook, J. Acouts. Soc. Am. 3\%, No. 3, 424-428 (Mar. 1965).

Contour charts are given of the sound fields near one, two, or three reflecting surfaces at right angles, for random sound incidence. The charts show contours of the mean-squaredpressure in decibels as a function of position in the region within 2 wavelengths of the boundary surfaces. The boundary conditions at the reflecting planes are pressure reflecting (normal velocity equal to zero) or pressure release (pressure equal to zero). By reciprocity, the charts also give the radiation resistance of a point source as a function of position near such reflectors. The formulas used are tabulated; they extend and in some places correct formulas given in an earlier paper (Journ. Acous. Soc. Am. 27, 247-258, March 1955). The features of the sound fields near the reflectors are discussed, and some applications to accoustics measurements in reverberant sound fields are considered.

Line profiles in the far-uv absorption spectra of the rare gases, U. Fano and J. W. Cooper, Phys. Rev. 13\%, No. 5A, A1364-A1379 (Mar. 1, 1965).

${ }^{*}$ One thermochemical calorie $=4.1840$ joules.
The line profiles of a dozen series of widely different appearance, observed recently in the rare gas optical absorption spectra between 20 and $100 \mathrm{ev}$, are analyzed by adapting and extending previously developed theory. Theory characterizes each profile by its line width, q-index and correlation coefficient $\rho$ and relates these parameters to matrix elements of the energy and of the electric dipole moment. Because the profiles result from interference effects, the signs of these matrix elements are highly relevant. Crude estimates of such, hitherto hardly accessible, matrix elements are obtained from experimental evidence and from atomic theory, are intercompared and found to be in general agreement. Similarities and differences among the line protiles are thereby tentatively explained. The connection of Rydberg series and absorption edges is discussed and the occurrence of downward jumps at some edges is explained. This exploratory investigation demonstrates how one can treat experimental data and surveys the kind and volume of information on the dynamies of highly and multiply excited atoms made accessible by recent experimental techniques.

Low temperature magnetic transitions in some rare-earth trichlorides, J. C. Eisenstein, R. P. Hudson, and B. W. Mangum, Phys. Rev. 137, No. 6A, A1886-A1895 (Mar. 15, $1965)$.

The magnetic susceptibilities of $\mathrm{CeCl}_{3}, \mathrm{PrCl}_{3}$, and $\mathrm{NdCl}_{3}$ single crystals and of polycrystalline $\mathrm{SmCl}_{3}$ have been measured in the temperature region between 0.2 and $4.2^{\circ} \mathrm{K}$. Each of these compounds exhibits somewhat anomalous behavior. $\mathrm{NdCl}_{3}$ has two sharp spikes in its susceptibility vs. T curve at $1.035^{\circ} \mathrm{K}$ and $1.74^{\circ} \mathrm{K}$. These spikes are strongly affected by a weak external field and also depend on the amplitude and frequency of the ac measuring field. $\mathrm{CeCl}_{3}$ has a single sharp spike in its susceptibility at $0.345^{\circ} \mathrm{K}$. $\mathrm{PrCl}_{3}$ and $\mathrm{SmCl}_{3}$ have rather broad maxima in their susceptibilities at about 0.7 and $0.4^{\circ} \mathrm{K}$, respectively.

It is shown, on the basis of a simple molecular field model, that the superexchange coupling between nearest neighbors is ferromagnetic while that between next nearest neighbors is antiferromagnetic. The two spikes in the $\mathrm{NdCl}_{3}$ susceptibility curve are ascribed to two successive cooperative magnetic transitions. An attempt is made to correlate in a quantitative way the temperatures of the transitions in $\mathrm{CeCl}_{3}$ and $\mathrm{NdCl}_{3}$, and to explain why no similar transitions were observed in $\mathrm{PrCl}_{3}$ and $\mathrm{SmCl}_{3}$.

Nonlinear ambipolar diffusion of an isothermal plasma across a magnetic field, E. R. Mosburg, Jr., and K. B. Persson, Phys. Fluids $\boldsymbol{\gamma}$, No. 11, 1829-1833 (Nov. 1964).

Solutions are presented of the first two moment equations, including nonlinear terms, for the ambipolar diffusion of an isothermal plasma across a magnetic field. The two geometries considered are the plane parallel case and the infinite cylinder with axial symmetry. The Bohm criterion is automatically satisfied by the solutions. It is shown that the singularity in the space derivative of the ambipolar drift velocity at the plasma boundary cannot be removed by an axial magnetic field of any strength. Thus the plasma drift velocity and the plasma density remain monotonic functions of the position coordinate. It is also shown under the assumptions of this theory, that the ambipolar space charge field is always directed outward and does not reverse direction in this isothermal approximation even for extremely high magnetic fields. One is forced to conclude that a realistic theory of ambipolar diffusion requires the consideration of the thermal gradients within the plasma.

\section{Other NBS Publications}

\section{J. Res. NBS 69C (Engr. and Instr.), No. 3 (July-Sept. 1965), $\$ 0.75$.}

Two-terminal dielectric measurements up to $6 \times 10^{8} \mathrm{~Hz}$. M. G. Broadhurst and A. J. Bur.

Improved ten-picofarad fused silica dielectric capacitor. R. D. Cutkosky and L. H. Lee. (See above abstracts). Errors in the series-parallel buildup of four-terminal resistors. C. H. Page. 
Centerable rotator for measuring properties of crystals. P. Saylor and H. B. Lowey.

Equipment for single-crystal growth from the melt suitable for substances with a low melting point. A. T. Horton and A. R. Glasgow. (See above abstracts).

Phase and amplitude contrast microscopy in partially coherent light. M. De and P. K. Mondal.

Exposure time relations for Kossel microdiffraction photographs. H. Yakowitz and D. L. Vieth.

Cartesian diver as a density comparator. H. A. Bowman and R. M. Schoonover. (See above abstracts).

Cryogenic behavior of selected magnetic materials. J. J. Gniewek and E. Ploge. (See above abstracts).

\section{Radio Sci. J. Res. NBS/USNC-URSI, 69D, No. 8 (Aug. 1965), $\$ 1.00$.}

"Ultra Low Frequency Electromagnetic Fields" Papers

Preface to "Ultra Low Frequency Electromagnetic Fields" Papers. W. H. Campbell and S. Matsushita.

Solar wind and its interaction with the magnetosphere. C. P. Sonett.

Schumann resonances. J. Galejs.

Earth-ionosphere cavity resonances and the propagation of ELF radio waves. J. R. Wait.

Resonances of the earth-ionosphere cavity observed at Cambridge, England. M. J. Rycroft.

Experimental results on the dynamics of the $F$ region. W. Becker, R. Rüster, and J. Klostermeyer.

Regular oscillations near $1 \mathrm{c} / \mathrm{s}$ observed at middle and low latitudes. L. Tepley.

Preliminary results of a micropulsation experiment at conjugate points. R. E. Gendrin and V. A. Troitskaya.

Some characteristics of geomagnetic pulsations at frequencies near $1 \mathrm{c} / \mathrm{s}$. W. H. Campbell and E. C. Stiltner.

Propagation of hydromagnetic waves in the magnetosphere. M. Sugiura.

Ionospheric perturbation (the roles played by the ionosphere in geomagnetic pulsations). S. Matsushita.

Effects of induced earth currents on low-frequency electromagnetic oscillations. A. T. Price.

Equatorial effects. R. Hutton.

Interpretation of early magnetic transients caused by highaltitude nuclear detonations. S. L. Kahalas and P. Newman.

Abstracts of ULF Conference papers not published in this issue.

\section{Regular Contributions}

A note on the application of pulse compression techniques to ionospheric sounding. D. C. Coll and J. R. Storey.

Comments on a paper "Measurement of the phase velocity of VLF propagation in the earth ionosphere waveguide", by F. K. Steele and C. J. Chilton. H. F. Bates.

Reply to H. F. Bates' Comments on "Measurement of the phase velocity of VLF propagation in the earth ionosphere waveguide" by F. K. Steele and C. J. Chilton. F. K. Steele and C. J. Chilton.

\section{Radio Sci. J. Res. NBS/USNC-URSI, 69D, No. 9 (Sept. 1965),} $\$ 1.00$.

Ground-based passive probing using the microwave spectrum of oxygen. E. R. Westwater.

Response of NBS microwave refractometer cavities to atmospheric variations. R. O. Gilmer, R. E. McGavin, and B. R. Bean.

Effects of rocket outgassing on rf experiments. W. Pfister and J. C. Ulwick. (See above abstracts).

Further analysis of propagation of plasma waves in a "spokewheel" magnetic field. R. R. Gold.

Measurement of group velocity of $17.8-\mathrm{kHz}$ VLF radio waves. W. D. Westfall.

On the radio noise level at low and very low frequencies in polar regions. T. Stockflet Jørgensen.

Experimental study on the circular loop antenna immersed shallowly in a conducting medium. K. Iizuka.

Directivity of uniformly spaced optimum endfire arrays with equal sidelobes. M. T. Ma.
Extension of Fock theory for currents in the penumbra region. V. H. Weston.

Isometric-circle interpretation of bilinear transformation and its application to VSWR minimization. J. G. Rudolph and D. K. Cheng.

Magneto-ionic propagation in inhomogeneous media. Part I. Transverse propagation. B. K. Banerjea. (See above abstracts).

Magneto-ionic propagation in inhomogeneous media. Part II. Oblique propagation. B. K. Banerjea. (See above abstracts).

Editorial comment on the scientific papers of Lord Rayleigh (John William Strutt). J. R. Wait.

Radio Sci. J. Res. NBS/USNC-URSI, 69D10 (Oct. 1965), $\$ 1.00$.

Irreversible power and radiation resistance of antennas in anisotropic ionized gases. K. S. H. Lee and C. H. Papas. Scattering resonances of a cylindrical plasma. W. M. Leavens.

Radiation patterns from plasma enclosed cylindrical hypersonic vehicles. J. H. Harris, A. T. Villeneuve, and L. A. Broca.

The Schumann resonances. R. K. Cole, Jr.

Atmospheric radio noise bursts in the LF band at Bangalore. S. V. C. Aiya and K. N. Lakshminarayan.

Influence of finite ground conductivity on the propagation of VLF radio waves. J. R. Wait and K. P. Spies.

Model experiments on propagation of groundwaves across an abrupt boundary at perpendicular incidence. R. J. King and S. W. Maley.

Reviews and selected abstracts in radio science.

Ionospheric radio propagation, K. L. Davies, NBS Mono. 80 (Apr. 1965), \$2.75.

Effects of thermal shrinkage on built-up roofing, W. C. Cullen, NBS Mono. 89 (Mar. 4, 1965), 10 cents.

Examination of liquefied petroleum gas liquid-measuring devices, M. W. Jensen, NBS Handb. 99 (Ápr. 23, 1965), 35 cents.

Systems engineering in ceramics. Proceedings of a symposium April 19, 1964, NBS Misc. Publ. 267 (May 1, 1965), $\$ 2.00$.

Builder's template hinges, CS9-65 (Jan. 15, 1965), 10 cents. (Supersedes CS9-33)

Aluminum alloy chain link fencing, CS269-65 (Mar. 1, 1965), 10 cents.

Steel medicine cabinets, NBS CS267-65 (Mar. 1, 1965), 10 cents.

Hide trim pattern for domestic cattlehides, NBS CS268-65. (Apr. 4, 1965) 10 cents.

Microwave reflection techniques for dense plasma diagnostics, S. Takeda and T. Tsukishima, NBS Tech. Note 256 (Mar. 10, 1965), 25 cents.

Practical aspects of the use of AC-DC transfer instruments, E. S. Williams, NBS Tech. Note 257 (Mar. 9, 1965), 15 cents.

Research on crystal growth and characterization at the $\mathrm{Na}$ tional Bureau of Standards July to December 1964, Ed. H. F. MeMurdie, NBS Tech. Note 260 (May 8, 1965), 50 cents.

Summary of current research on archival microfilm, C. S. McCamy and C. I. Pope, NBS Tech. Note 261 (Apr. 16, 1965), 25 cents.

Bibliography of fading on microwave line of sight tropospheric propagation paths and associated subjects, H. T. Dogherty, NBS Tech. Note 302 (Áug. 31, 1964), 60 cents.

Bibliography on tropospheric propagation of radio waves, W. Nupen, NBS Tech. Note 304 (Ápr. 1, 1965), $\$ 2.00$.

Atlas of Fourier coefficients of diurnal variation of $f \mathrm{o} F_{2}$ Part II. Distribution of amplitude and phase, W. B. Jones and R. M. Gallet, NBS Tech. Note 305 (Feb. 14, 1965), 60 cents.

Studies of solar flare effects and other ionospheric disturbances with a high frequency Doppler technique, V. Ágy, D. M. Baker, and R. M. Jones, NBS Tech. Note 306, (Apr. 28, 1965), 75 cents. 
Phase and amplitude diversity in over-water transmissions at two microwave frequencies, H. B. Janes, A. W. Kirkpatrick, D. M. Waters, and D. Smith, NBS Tech. Note 307 (Apr. 12, 1965), 40 cents.

Data reduction for stable auroral red ares observed at Rapid City, South Dakota, J. E. Cruz, R. Davies, L. K. Droppleman, E. Marovich, L. R. Megill, M. H. Rees, L. Reisbeck, and F. E. Roach, NBS Tech. Note 308 (May 3, 1965), 50 cents.

A bibliography of experimental saturation properties of the cryogenic fluids, N. A. Olien and L. A. Hall, NBS Tech. Note 309 (Ápr. 9, 1965), 60 cents.

Attenuation of the ground wave of a low-frequency electromagnetic pulse, J. C. Morgenstern and J. R. Johler, NBS Tech. Note 310 (Apr. 1965). 30 cents.

Blood: Bone equilibrium in calcium homoeostasis, $\mathrm{J}$. MacGregor and W. E. Brown, Nature 205, No. 4969, 359-361 (Jan. 23, 1965).

Carbon monoxide on niobium, R. Klein and J. W. Little, Surface Science 2, 167-176 (North-Holland Publ. Co., Amsterdam, The Netherlands, 1964).

Fracture in corrosive media, H. L. Logan, Book, Fracture of Engineering Materials, ch. 8, pp. 143-161 (American Society for Metals, Metals Park, Ohio, Nov. 1964).

Gas-phase radiolysis of $n$-pentane. A study of the decompositions of the parent ion and neutral exicted pentane molecule, P. Ausloos and S. G. Lias, J. Chem. Phys. 41, No. 12, 3962-3970 (Dec. 15, 1964).

Impedance of sealed nickel-cadmium dry cells, R. J. Brodd and H. J. DeWane, Electrochem. Tech. 3, No. 1-2, 12-17 (Jan.-Feb. 1965).

Moderation in instrumentation, J. K. Taylor, Science Teacher 32, No. 3, 18-19 (Mar. 1965).

Pressure-indicator-paste patterns in duplicate dentures made by different processing technics for the same patients, J. B. Woelfel and G. C. Paffenbarger, J. Am. Dental Assoc. 70, 339-343 (Feb. 1965).

Radioisotope dilution and its application to the radioassay of $\mathrm{Ce}^{144}$, L. A. Currie, G. M. France, III, and H. L. Steinberg, Intern. J. Appl. Radiation Isotopes 16, No. 1, 1-8 (Jan. 1965).

Reference buffer solutions for $p \mathrm{H}$ measurements in $50 \%$ methanol. Dissociation constants of acetic acid and dihydrogen phosphate ion from 10 to $40^{\circ}$, M. Paabo, R. A. Robinson, and R. G. Bates, J. Am. Chem. Soc. 87, 415-418 (1965).

Resins and technics used in constructing dentures, G. C. Paffenbarger, J. B. Woelfel, and W. T. Sweeney, Dental Clinics of North America, pp. 51-262 (W. B. Saunders Co., Philadelphia, Pa., 1965).

Spectra of matrix-isolated $\mathrm{NiF}_{2}$ and $\mathrm{NiCl}_{2}, \mathrm{D}$. E. Milligan, M. E. Jacox, and J. D. MeKinley, J. Chem. Phys. 42, No. 3, 902-905 (Feb. 1965).

The polarographic analysis of titanium (IV)-EDTA complex: Application to paint pigments, H. W. Berger and B. C. Cadoff, Offic. Digest Paint Tech. 37, No. 480, 28-34 (Jan. 1965).

The structures of anhydrous sodium trimetaphosphate, $\mathrm{Na}_{3} \mathrm{P}_{3} \mathrm{O}_{9}$, and the monohydrate, $\mathrm{Na}_{3} \mathrm{P}_{3} \mathrm{O}_{9} \cdot \mathrm{H}_{2} \mathrm{O}$, H. M. Ondik, Acta. Cryst. 18, Part 2, 226-232 (Feb. 1965).

Vacuum ultraviolet photochemistry. VIII. Propylene, D. A. Becker, H. Ikabe, and J. R. McNesby, J. Phys. Chem. 69, No. 2, 538-542 (Feb. 1965).

A magnetic amplifier for use with diode logic, E. W. Hogue, IEEE Trans. Commun. Electron. 83, No. 75, 803-808 (Nov. 1964).

A study of the variation of the surface electrical resistance of lead iodide films with relative humidity at room temperature, F. E. Jones (Proc. 1963 Intern. Symp. Humidity and Moisture, Washington, D.C.), Book, Humidity and Moisture. Measurement and Control in Science and Industry. Vol. 1, Principles and Methods of Measuring Humidity in Gases, Sec. III, Paper 37, pp. 361-365 (Reinhold Publ. Corp., New York, N.Y., 1965).

An investigation of psychrometric measurement techniques in air-conditioning calorimetry, J. C. Davis and P. R. Achenbach (Proc. 1963 Intern. Symp. Humidity and Moisture, Washington, D.C.), Eook, Humidity and Moisture.
Measurement and Control in Science and Industry. Vol. 2, Applications, Sec. IV, Paper 37, pp. 303-313 (Reinhold Publ. Corp., New York, N.Y., 1965).

Application of cooled air detector in an optical system, S. Abramowitz, A. M. Bass, and A. E. Ledford, Jr., Appl. Opt. 4, No. 2, p. 255 (Feb. 1965).

Calculation of the temperature of a flat-plate wet surface under adiabatic conditions with respect to the Lewis relation, T. Kusuda (Proc. 1963 Intern. Symp. Humidity and Moisture, Washington, D.C.), Book, Humidity and Moisture. Measurement and Control in Science and Industry. Vol. 1, Principles and Methods of Measuring Humidity in Gases, Sec. I, Paper 2, pp. 16-32 (Reinhold Publ. Corp., New York, N.Y., 1965).

Clinical behavior of $o$-ethoxybenzoic acid-eugenol-zinc oxide cements, S. Civjan and G. M. Brauer, J. Dental Res. 44, No. 1, 80-83 (Jan.-Feb. 1965).

Control of relative humidity and temperature in rubber laboratory of National Bureau of Standards, F. L. Roth and R. D. Stiehler (Proc. 1963 Intern. Sypm. Humidity and Moisture. Washington, D.C.), Book, Humidity and Moisture. Measurement and Control in Science and Industry. Vol. 2, Applications, Sec. III, Paper 35, pp. 287-292 (Reinhold Publ. Corp., New York, N.Y., 1965).

Measurement of radiation dose distributions with photochromic materials, W. E. McLaughlin and L. Chalkley, Radiology 84, No. 1, 124-125 (Jan. 1965).

Soil corrosion, W. J. Schwerdtfeger, Encyclopedia of Electrochemistry, pp. 1068-1071 (Reinhold Publ. Corp., New York, N.Y., Mar. 1965).

A theorem on the automorphs of a skew-symmetric matrix, M. Newman, Mich. Math. J. 12, 61-63 (1965).

On the location of the zeros of some infrapolynomials with prescribed coefficients, J. L. Walsh and O. Shisha, Pacific J. Math. 14, No. 3, 1103-1109 (1964).

On the structure of infrapolynomials with prescribed coefficients, O. Shisha, Pacific J. Math. 14, No. 3, 1039-1051 (1964).

Continuous-absorption hygrometry with a pneumatic bridge utilizing critical flow, W. A. Wildhack, T. A. Perls, C. W. Kissinger, and J. W. Hayes (Proc. 1963 Intern. Symp. Humidity and Moisture, Washington, D.C.), Book, Humidity and Moisture. Measurement and Control in Science and Industry. Vol. 1. Principles and Methods of Measuring Humidity in Gases, Sec. VI, Paper 53, pp. 552-570 (Reinhold Publ. Corp., New York, N.Y., 1965).

Comment on the difference between a non-LTE and a pure absorption model for the line-blanketing effect, R. N. Thomas, Astrophys. J. 141, 333-335 (Jan. 1, 1965).

Displacement of dislocation images formed in transmission electron microscopy, R. DeWit, J. Appl. Phys. 36, No. 1, 329-330 (Jan. 1965).

On the relative roles of free volume and activation energy in the viscosity of liquids, P. B. Macedo and T. A. Litovitz, J. Chem. Phys. 42, No. 1, 245-256 (Jan. 1, 1965).

On trapped trajectories in Brownian motion, J. L. Jackson and S. R. Coriell, J. Math. Phys. 5, No. 8, 1075-1078 (Aug. 1964)

Reaction ${ }^{59} \mathrm{Co}(p, \alpha)^{56} \mathrm{Fe}$, M. Barloutaud, R. S. Caswell, J. Gasteblis, A. G. de Pinho, and J. Quidort (Proc. Intern. Congress Nuclear Physics, Paris, France, July 2-8, 1964), Compt. Rend. Cong. Intern. Phys. Nucleaire II, 717-719 (Centre National de la Recherche Scientifique, Paris, France, 1964).

Screening effects in elastic electron scattering, E. Zeithler and H. Olsen, Phys. Rev. 136, No. 6A, A1546-A1552 (Dec. 14, 1964).

Stability of the shape of a solid cylinder growing in a diffusion field, R. L. Parker and S. R. Coriell, J. Appl. Phys. 36, No. 2, 632-637 (Feb. 1965).

The intensity and spectral distribution of scattered radiation from $\mathrm{Co}^{60}$ sources, B. Petree and J. C. Humphreys, Radiology 84, No. 1, 129-130 (Jan. 1965).

The interaction of $350 \mathrm{keV}$ polarized neutrons with oriented $\mathrm{Ho}^{165}$ nuclei, R. Wagner, P. D. Miller, T. Tamura, and H. Marshak, Phys. Letters 10, No. 3, 316-318 (June 15, 1964).

Zeeman filter, D. G. Dessler and W. G. Schweitzer, Jr., J. Opt. Soc. Am. 55, No. 3, 284-288 (Mar. 1965). 
Cosmic noise absorption events at geomagnetically conjugate stations, C. G. Little, E. R. Schiffmacher, H. J. A. Chivers and K. W. Sullivan, J. Geophys. Res. \%o, No. 3, 639-648 (Feb. 1, 1965).

Fluctuations in a laser beam over 9 - and 90 -mile paths, W. R. Hinchman and A. L. Buck, Proc. IEEE 52, No. 3, 305306 (Mar. 1964)

On the effect of solar disturbances on the low-radiofrequency ionosphere reflection process, J. R. Johler and J. D. Harper Jr. (North Átlantic Treaty Organization Advisory Group for Aeronautical Research and Development. Avionics Panel. 6th Symp. Ionospheric Research Committee, AGARD., Naples, Italy, 1961), Book, The Effect of Disturbances of Solar Origin on Communications, ed. G. J. Gassman, pp. 303-304 (Pergamon Press, Inc., New York, N.Y., 1963).

A line-formula notation system for coordination compounds, P.M. McDonnell and R. F. Pasternack, J. Chem. Documentation 5, No. 1, 56-60 (Feb. 1965). Decyclization of cyclohexene, 4-methylcyclohexene, and 4-vinylcyclohexene in a single-pulse shock tube, W. Tsang, J. Chem. Phys. 42, No. 5, 1805-1809 (Mar. 1, 1965).

Hydrogen atom addition to olefins: Relative rates at the two carbon positions and derived heats of formation of several alkyl radicals, R. D. Kelley, R. Klein, and M. D. Scheer, J. Phys. Chem. 69, No. 3, 905-908 (Mar. 1965).

Isotopic mixing in $\mathrm{CO}$ chemisorbed on tungsten. A kinetic study, T. E. Madey, J. T. Yates, Jr., and R. C. Stern, J. Chem. Phys. 42, No. 1, 1372-1378 (Feb. 15, 1965).

Some new co-ordination compounds of copper (II) chloride, C. Reimann and G. Gordon, Nature 205, No. 4974, 902-903 (Feb. 27, 1965).

Standardization of analytical data obtained with silver-silver chloride electrodes in methanol-water solvents, M. Paabo, R. G. Bates, and R. A. Robinson, Anal. Chem. 37, 462-464 (1965).

Watermarks for papermaking by electroforming, J. P. Young, Tappi 48, No. 1, 36A-37A (Jan. 1965); Metal Finishing $6 \mathbf{6 3}$ No. 4, 79-82 (Apr. 1965)

Latensification in radiographic emulsions, W. L. McLaughlin, J. Photo. Sci, 13, 1-11 (1965)

On the information in a microphotograph, C. S. McCamy, Appl. Opt. 4, No. 4, 405-411 (Apr. 1965).

Results of National Bureau of Standards corrosion investigation in disturbed and undisturbed soils, M. Romanoff, Proc. Appalachian Underground Short Course, Tech. Bull. 72, p. 566-589 (West Virginia Univ., Morgantown, West Va, 1965)

Statistical design of experiments, W. J. Youden, Handbook on Metals Engineering-Design, American Society of Mechanical Engineers, ch. 3, pt. 5, pp. 583-585 (McGrawHill Publ. Corp., New York, N.Y., 1965).

Technique for determining spin-lattice relaxation times, G. A. Candela and R. E. Mundy, Rev. Sci. Instr. 36, No. 3, 338-342 (Mar. 1965).

Two cases of stress corrosion cracking in copper tubing, H. L. Logan and G. M. Uginsky, Materials Protection 4, No. 3, 79-80 (May 1965).

A uniqueness theorem for entire functions, R. F. DeMar, Proc. Am. Math. Soc. 16, No. 1, 59-71 (Feb. 1965).

Nomograms for computing real, imaginary, and absolute values of vector ratios, H. S. Bowman, Acoust. Soc. Ám. 3\%, No. 4, 751 (Apr. 1965).

On a theorem concerning existence of interpolating functions, R. F. DeMar, Trans. Am. Math. Soc. 114, No. 1, 23-29 (Jan. 1965)

A study of errors in the measurement of microscopic spheres, C. P. Saylor, Appl. Opt. 4, No. 4, 477-486 (Ápr. 1965).

Definition of "ampere" and "magnetic constant," C. H. Page, Proc. IEEE 53, No. 1, 100-101 (Jan. 1965).

Electromagnetic measurement, $\mathrm{H}$. W. Lance, SPACE AERONAUTICS Res. Develop. Handb. 42, No. 4, 199-202 (1964-1965).

A proper accounting of conformation of a polymer near a surface, E. A. DiMarzio, J. Chem. Phys. 42, No. 6, 21012106 (Mar. 1965)

A test of analytical expressions for the thermal emissivity of shallow cylindrical cavities, F. J. Kelly and D. G. Moore, Appl. Opt. 4, No. 1, 31-40 (Jan. 1965).
A universal color language, K. L. Kelly, Color Eng. 3, No. 2, 16-21 (Mar.-Apr. 1965).

Characteristics of the "synchrotron light" from the NBS-180 MeV machine, K. Codling and R. P. Madden, J. Appl. Phys. 36, No. 2, 380-387 (Feb. 1965).

Dependence of the superconducting transition temperature on carrier concentration in semiconducting $\mathrm{SrTiO}_{3}, \mathrm{~J}$. F. Schooley, W. R. Hosler, E. Ámbler, J. H. Becker, M. L. Cohen, and C. S. Koonce, Phys. Rev. Letters 14, No. 9, 305-307 (Mar. 1, 1965).

Growth layers on ammonium dihydrogen phosphate. J. L. Torgesen and R. W. Jackson, Science 148, No. 3672, 952954 (May 14, 1965).

High silica glass, quartz, and vitreous silica, J. S. Laufer, J. Opt. Soc. Ám. 55, No. 4, 458-460 (Ápr. 1965).

Influence of paramagnetic resonance on the static susceptibility. Spin-lattice relaxation time of cupric sulfate pentahydrate, G. A. Candela, J. Chem. Phys. 42, No. 1, 113-117 (Jan. 1, 1965).

Multichannel resonances in the forward scattering of electrons by helium, G. E. Chamberlain, Phys. Rev. Letters 14, No. 15, 581-582 (Apr. 12, 1965).

Polymorphism in hydrogen iodide, F. A. Mauer, C. J. Keffer, R. B. Reeves, and D. W. Robinson, J. Chem. Phys. 42, No. 4, 1465-1466 (Feb. 15, 1965).

Stability of traveling waves in lasers, J. A. White, Phys. Rev. 137, No. 6A, Á1651-A1654 (Mar. 15, 1965).

Temperature and mean free path dependence of the Ginzburg-Landau parameter, S. Gygax and R. H. Kropschot, Phys. Letters 12, No. 1, 7-9 (Sept. 1, 1964).

The measurement of water vapor boundary layers in biological systems with a radio refractometer, D. M. Gates (Proc. 1963 Intern. Symp. Humidity and Moisture, Washington, D.C.), Book, Humidity and Moisture. Measurement and Control in Science and Industry. Vol. 2. Applications, Sec. I, Paper 5, pp. 33-38 (Reinhold Publ. Corp., New York, N.Y., 1965)

The use of terahertz photobeats for precise velocity-of-light measurement, Z. Bay and H. s. Boyne, Proc. Enrico Fermi International School of Physics: Course No. XXXI Quantum Electronics and Coherent Light 1963, 352-371 (1964).

Two-electron excitation states in helium, R. P. Madden and K. Codling, Astrophys. J. 141, No. 2, 362-375 (Feb. 15, 1965)

Cavity resonances for spherical earth with a concentric anisotropic shell, J. R. Wait, J. Atmos. Terres. Phys. 27, 81-89 (1965).

Potential use of passive probing of atmospheric structure by thermal emissions at radio frequencies, B. R. Bean, E. R. Westwater, and R. L. Abbott (Proc. 1963 Intern. Symp. Humidity and Moisture, Washington, D.C.), Book, Humidity and Moisture. Measurement and Control in Science and Industry. Vol. 2, Applications, Sec. VII, Paper 71, pp. 595-608 (Reinhold Publ. Corp., New York, N. Y., 1965). Radio refractometry and its potential for humidity studies, R. E. McGavin and M. J. Vetter (Proc. 1963 Intern. Symp. Humidity and Moisture, Washington, D.C.), Book, Humidity and Moisture. Measurement and Control in Science and Industry. Vol. 2. Applications, Sec. VII, Paper 66, pp. 553-560 (Reinhold Publ. Corp., New York, N.Y., 1965)

The use of the radio refractometer to measure water vapor turbulence, B. R. Bean and R. E. McGavin (Proc. 1963 Intern. Symp. Humidity and Moisture, Washington, D.C.), Book, Humidity and Moisture. Measurement and Control in Scienceand Industry. Vol. 2. Ápplications, Sec. VII, Paper 67, pp. 561-568 (Reinhold Publ. Corp., New York, N.Y., 1965).

*Publications for which a price is indicated are available by purchase from the Superintendent of Documents, U.S. Government Printing Office, Washington, D.C., 20402 (foreign postage, one-fourth additional). Reprints from outside journals and the NBS Journal of Research may often be obtained directly from the authors. 